Case Report

\title{
Clinical profile of severe anemia in adolescents from a hilly terrain tertiary care hospital in north India
}

\author{
Kumar P. ${ }^{1}$, Sharma S. ${ }^{2}$, Sharma M. ${ }^{3}$, Patel A. ${ }^{4}$ \\ ${ }^{1}$ Dr. Pradeep Kumar, Senior Resident, ${ }^{2}$ Dr. Seema Sharma, Associate Professor, ${ }^{3}$ Dr. Milap Sharma, Assistant Professor, \\ ${ }^{4}$ Dr. Ashish Patel, Junior Resident, all authors are affiliated with Department of Pediatrics, Dr. Rajendra Prasad Govt. \\ Medical College, H.P, India.
}

Corresponding Author: Dr. Seema Sharma, House No 23, Block-B, Type-V, DR. RPGMCH, Kangra at Tanda, H.P. India. E-mail: dr.seema73.ss@gmail.com, E mail: seema406@rediffmail.com

\begin{abstract}
Introduction: Adolescence is a vulnerable period for development of anemia. Anemia in adolescence has serious implications for a wide range of outcomes. It causes reduced resistance to infection, impaired physical growth and mental development, reduced physical fitness, work capacity and school performance. Objectives: The aim of the present study was to study the clinical profile of the adolescents (10-18 years) admitted with severe anemia. Methods: A hospital based retrospective study was conducted in the Department of Pediatrics, Dr Rajendra Prasad Government Medical College Kangra, a tertiary care institute in North India, during the period from January 2015 to December 2016. The participants in our study were the adolescent patients (10-18 years) admitted with primary diagnosis of severe anemia (Hemoglobin $<7 \mathrm{gm} \%$ ). The diagnosis of type of anemia was based on hematological indices and red cell morphology on peripheral smear. Results: There were 39 patients admitted with severe anemia. This constituted $1.90 \%$ of all the admissions during the study period. The mean age of the patients was $14.97( \pm 1.86)$ years and the mean hemoglobin was $4.66( \pm 1.28) \mathrm{gm} \%$. There was a female preponderance with $66.67 \%$ females as against $33.33 \%$ males. Megaloblastic anemia was the most common type of anemia (52.28\%) followed by iron deficiency anemia $(30.77 \%)$ and dimorphic anemia $(15.38 \%)$. All of the patients belonged to poor socioeconomic status and most of them $(89.74 \%)$ were vegetarian. Conclusion: Although iron deficiency anemia is the most common type of anemia in India, yet in adolescents megaloblastic and dimorphic anemia should be looked for whenever the adolescents present with severe anemia especially in the setting of malnutrition and dietary inadequacy.
\end{abstract}

Keywords: Adolescence, Anemia, Megaloblastic anemia

\section{Introduction}

Anemia is a major health problem worldwide. It affects mostly preschool children, adolescents and pregnant women. There are about 1.2 billion adolescents in the world, which is equal to $1 / 5$ th of the world's population and their numbers are increasing. Out of these, 5 million adolescents are living in developing countries. India's population has crossed the 1 billion mark, out of which $21 \%$ are adolescents [1].

Adolescent period is very crucial, since these are the formative years in the life of an individual, when major physical, psychological and behavioral changes take place. The nutritional and the health needs of the adolescents are also more because of the growth spurt and the increase in physical activity in them [2].

Manuscript received: $8^{\text {th }}$ September 2018

Reviewed: $18^{\text {th }}$ September 2018

Author Corrected: $26^{\text {th }}$ September 2018

Accepted for Publication: $30^{\text {th }}$ September 2018
In females, adolescence also marks the beginning of the menstrual cycle or reproduction. Adolescent girls are, therefore, at a high risk for anemia and malnutrition. Inadequate nutrition during adolescence can have serious consequences throughout their reproductive years of life and beyond [3]. Very often, in India, girls get married and pregnant even before the growth period is over, thus doubling the risk for anemia [4].

Iron deficiency anemia is the most prevalent anemia in adolescent age group in India. Several community studies have reported upto $60 \%$ of adolescents having iron deficiency anemia [5,6]. Some community based studies showed that megaloblastic anemia is also common in India. However, severe anemia is uncommon and can have varied etiology $[7,8]$. Hospital based studies on patients admitted with severe anemia are lacking. So, the present study was conducted to find 
Case Report

the profile of adolescent (10-18 Years) patients with primary diagnosis of severe anemia in a tertiary care hospital.

\section{Material and Methods}

Place of study- The present study was conducted in the Department of Pediatrics, Dr Rajendra Prasad Government Medical College Kangra, a tertiary care institute in North India.

Type of study- The present study was a hospital based retrospective study conductedduring the period from January 2015 to December 2016. The participants in our study were the adolescent patients (10-18 years) admitted with primary diagnosis of severe anemia $($ Hemoglobin $<7$ gm \%).

Inclusion Criteria- All the patients in the age group of 10-18 years with severe anemia requiring hospital admission for the first time due to anemia were included in the study group.

Exclusion Criteria- The patients, who had other comorbid conditions causing anemia like hematological malignancy, chronic illness like chronic renal failure, immunodeficiency, tuberculosis etc. were excluded from the study. The cases that were diagnosed previously and were admitted for either transfusions of blood or its components or for other reasons were also excluded from the study.

Data collection- Out of all patients admitted in Dr Rajendra Prasad Government Medical College Kangra from January 2015 to December 2016, adolescent patients (10-18 years) were selected. Out of these adolescent, case files of those admitted with severe anemia for the first time were reviewed.

Investigations- All the study cases had undergone complete hemogram and peripheral smear examination. The hemoglobin was estimated by Sahli's method and expressed in gm\%, peripheral smear was stained by Leishman's stain. PCV, MCV, MCH, MCHC and RDW were determined by automated cell counter. Normal values were taken as follows: PCV $35-45 \%$, MCV $77-$ 95fl, MCH 25-33pg, MCHC 31-37gm/dl and RDW 14.5-18.5. Reticulocyte count was done by Brilliant crystal stain method. Vitamin B12 levels, serum folate levels, iron studies and bone marrow examination could not be done in all the patients due to financial constrains. Hence, the diagnosis of type of anemia was based on hematological indices and red cell morphology on peripheral smear.

Diagnostic criteria for type of anemia- The diagnosis of type of anemia was based on hematological indices and red cell morphology on peripheral smear.

\section{Results}

A total of 8635 patients were admitted in pediatric wards at this institute from January 2015 to December 2016, of which 2053 (23.78\%) belonged to adolescent age group (10-18 years). Out of 2053 adolescent patients 1159 (56.45\%) were male and $894(43.55 \%)$ were female. $39(1.90 \%)$ of these adolescent patients were admitted with the primary diagnosis of severe anemia $(\mathrm{Hb}<7 \mathrm{gm} / \mathrm{dl})$.

Among the 39 patients, 13 (33.33\%) were male and 26 (66.67\%) were female patients. Maximum number of 19 (48.72\%) patients was from age group 13-15 years, followed by $16(40.02 \%)$ patients from age group 16-18 years. (Table 1$)$

Table- 1: Age and sex wise distribution of patients with severe anemia.

\begin{tabular}{|c|c|c|c|}
\hline Age Group & Male & Female & Total \\
\hline $10-12$ Year & 1 & 3 & 4 \\
\hline $13-15$ Year & 7 & 12 & 16 \\
\hline $16-18$ Year & 5 & 11 & 39 \\
\hline
\end{tabular}

Most patients presented with easy fatigability (84.62\%), Breathlessness on exertion (61.54\%) and progressive paleness (58.97\%). Other important symptoms on presentation were decreased appetite $(30.77 \%)$, palpitations $(20.51 \%)$, fever (15.38\%), lethargy (12.82\%), pain abdomen (7.69\%) and swelling over body (5.13\%). Most common findings were pallor (100\%), splenomegaly $(58.97 \%)$ and hepatomegaly $(53.85 \%)$. Other important signs detected were haemic murmur (33.33\%), knuckle hyperpigmentation (25.64\%) and icterus (17.95\%). Signs of congestive cardiac failure were present in $17.95 \%$ patients. Tongue and nail changes were observed in $17.95 \%$ and $15.38 \%$ patients respectively. 
Case Report

Table-2: Distribution of the patients as per the clinical feature.

\begin{tabular}{|c|c|c|}
\hline \multicolumn{2}{|c|}{ Number } & Percentage \\
\hline Clinical Features & 33 & 84.62 \\
\hline Easy Fatigability & 24 & 61.54 \\
\hline Breathlessness on exertion & 23 & 58.97 \\
\hline Progressive paleness & 12 & 30.77 \\
\hline Decreased appetite & 8 & 20.51 \\
\hline Palpitations & 6 & 15.38 \\
\hline Fever & 5 & 12.82 \\
\hline Lethargy & 2 & 7.69 \\
\hline Pain abdomen & 2 & 5.13 \\
\hline Swelling over body & 39 & 100 \\
\hline Pallor & 23 & 58.97 \\
\hline Splenomegaly & 21 & 53.85 \\
\hline Hepatomegaly & 13 & 33.33 \\
\hline Haemic murmur & 10 & 25.64 \\
\hline Knuckle hyperpigmentation & 7 & 17.95 \\
\hline Icterus & 7 & 17.95 \\
\hline Congestive cardiac failure & 6 & 17.95 \\
\hline Nongue changes & \multicolumn{2}{|c|}{} \\
\hline
\end{tabular}

On peripheral smear examination microcytic hypochromic picture was seen in $12(30.77 \%)$, macrocytic hypochromic picture was seen in $20(51.28 \%)$ and dimorphic picture was seen in $6(15.38 \%)$ of patients.In 01 (2.56\%) patient normocytic normochromic picture was detected.

In the current study megaloblastic anemia was most common followed by iron deficiency anemia and dimorphic anemia. (Figure 1) Iron deficiency anemia was found in $12(30.77 \%)$ patients, the prevalence being more in females i.e. $20.51 \%$ as against $10.25 \%$ in males. The megaloblastic anemia was found in $20(51.28 \%)$ patients, with $13(33.33 \%)$ female as against $7(17.94 \%)$ male patients. The dimorphic anemia was detected in $6(15.38 \%)$ patients, with 5 (12.82\%) female and $01(2.56 \%)$ male patients. One patient $(2.56 \%)$ was found to have aplastic anemia.

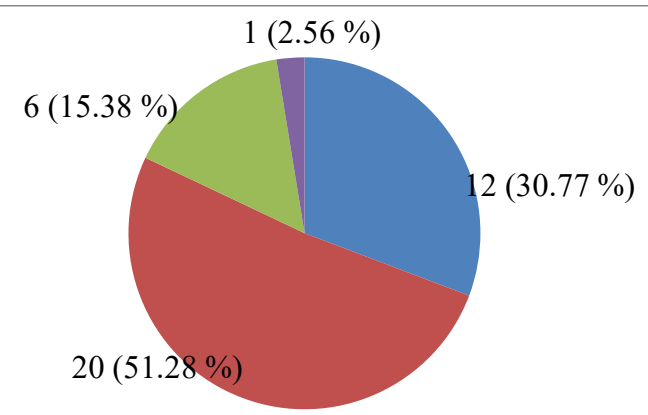

Iron deficiency anemia

- Megaloblastic anemia

Dimorphic anemia

- Aplastic anemia

Figure 1: Prevalence of different types of anemia

In iron deficiency anemia $\mathrm{MCV}, \mathrm{MCH}$ and $\mathrm{MCHC}$ were found decreased. In megaloblastic anemia $\mathrm{MCV}$ and $\mathrm{MCH}$ were increased whereas MCHC was found normal. In dimorphic anemia variations were seen in these red cell indices. RDW was done in 24 patients. It was found increased in cases of iron deficiency anemia and dimorphic anemia. Reticulocyte count was done only in 10 patients and it was normal in all these patients. (Table 3 ) 
Case Report

Table-3: Relation of RBC indices in anemia.

\begin{tabular}{|c|c|c|c|c|}
\hline Parameter & $\begin{array}{c}\text { Iron deficiency } \\
\text { anemia }\end{array}$ & $\begin{array}{c}\text { Megaloblastic } \\
\text { anemia }\end{array}$ & Dimorphic anemia & Aplastic anemia \\
\hline MCV Normal & & & $2(5.13 \%)$ & $1(2.56 \%)$ \\
\hline MCV Decreased & $12(30.77 \%)$ & & & \\
\hline MCV Increased & & $20(51.28 \%)$ & $4(10.26 \%)$ & \\
\hline MCH Normal & & $2(5.13 \%)$ & $2(5.13 \%)$ & $1(2.56 \%)$ \\
\hline MCH Decreased & $12(30.77 \%)$ & & & \\
\hline MCH Increased & & $18(46.15 \%)$ & $4(10.26 \%)$ & \\
\hline MCHC Normal & $1(2.56 \%)$ & $20(51.28 \%)$ & $5(12.82 \%)$ & $1(2.56 \%)$ \\
\hline MCHC Decreased & $11(28.21 \%)$ & & & \\
\hline RDW Normal & $3(7.69 \%)$ & $8(20.51 \%)$ & & \\
\hline RDWDecreased & & $1(2.56 \%)$ & & \\
\hline RDW Increased & $5(12.82 \%)$ & $3(7.69 \%)$ & $4(10.26 \%)$ & \\
\hline
\end{tabular}

$\mathrm{MCV}$, mean corpuscular volume; $\mathrm{MCH}$, mean corpuscular hemoglobin; MCHC, mean corpuscular hemoglobin concentration; RDW, red cell distribution width.

Most of the patients in this study belonged to class V (53.85\%) followed by class IV (43.85\%) while one (2.56\%) patient belonged to class III of modified Kuppuswamy socioeconomic scale.

Most of the patients in this study were vegetarian (89.74\%). Out of 13 male patients $12(92.31 \%)$ and out of 26 female patients $23(88.46 \%)$ were vegetarian. The non-vegetarian constituted only $10.26 \%$ of the patients. $74.36 \%$ of the patients had calories and protein deficit. Severe thinness (BMI <-3SD) was found in $15.38 \%$ patients and thinness (BMI -2SD to 3SD) was found in $35.64 \%$ of the patients. Rest of the patients had normal BMI.

Most the patients in this study were symptomatic from 15-30 days (51.28\%). However, 25.64\% of the patients presented with symptoms of duration less than 15 day and $23.07 \%$ of the patients had symptoms for more than 30 day at presentation. The mean duration of hospital stay was $6.5( \pm 2.5)$ days.

In this study $10.26 \%$ patients with iron deficiency anemia, $15.38 \%$ patients with megaloblastic anemia and $7.69 \%$ patients with dimorphic anemia were transfused packed red blood cells. The remaining patients were managed by oral hematinics and $\mathrm{B} 12$ as per protocol.

\section{Discussion}

Adolescence is the formative period of life when the maximum amount of physical, psychological, and behavioral changes take place. This is a vulnerable period in the human life cycle for the development of nutritional anemia [9]. Anemia has a negative effect on cognitive performance in adolescents [10]. Compared to the vast amount of work done in pregnant mothers and young children, there are relatively few published studies in India evaluating nutritional anemia and its association with severity of anemia [10].

The present study was conducted to find the profile of adolescent patients admitted with severe anemia. This was a hospital based study on 39 adolescent patients with a 1:2 male-female ratio. The females outnumbered males. The present study was in accordance with Khanduri et.al [11] and Salma Haq et.al [12] with a female preponderance.

In the present study the incidence of adolescent patients hospitalized with a primary diagnosis of severe anemia was found to be $1.90 \%$ where as in a similar study by Patra et al. [7], have reported the incidence of $3.37 \%$. Though iron deficiency anemia has been reported as most prevalent anemia in adolescent age group in India $[5,6]$, the commonest type of anemia in the present study was megaloblastic anemia (51.28\%) followed by iron deficiency anemia (30.77\%) and dimorphic anemia $(15.38 \%)$. One case of aplastic anemia $(2.56 \%)$ was also found. In the study by Patra, et al[7] on severely anemic 
Case Report

adolescents admitted in a tertiary care hospital, megaloblastic anemia was most common type of anemia $(42.5 \%)$. This was followed by aplastic anemia $(27.5 \%)$ and iron-deficiency accounting for $15 \%$ cases.

Easy fatigability $(84.62 \%)$, breathlessness on exertion $(61.54 \%)$ and progressive paleness $(58.97 \%)$ were the most common symptoms. Other important symptoms on presentation were decreased appetite (30.77\%), palpitations (20.51\%), fever $(15.38 \%)$, lethargy $(12.82 \%)$, pain abdomen (7.69\%) and swelling over body $(5.13 \%)$. Most common findings were pallor $(100 \%)$, splenomegaly $(58.97 \%)$ and hepatomegaly (53.85\%). Other important signs detected were haemic murmur(33.33\%), knuckle hyperpigmentation (25.64\%) and icterus (17.95\%). Signs of congestive cardiac failure were present in $17.95 \%$ patients. Tongue and nail changes were observed in $17.95 \%$ and $15.38 \%$ patients respectively. Theses clinical features were similar to earlier studies on clinical profile of anemia in children $[13,14]$.

In iron deficiency anemia $\mathrm{MCV}, \mathrm{MCH}$ and $\mathrm{MCHC}$ were found decreased. In megaloblastic anemia MCV and $\mathrm{MCH}$ were increased whereas $\mathrm{MCHC}$ was found normal. In dimorphic anemia variations were seen in these red cell indices. This is in accordance with the previous studies $[15,16]$.

Global anemia prevalence statistics show that the incidence is higher in developing countries and significantly high in poor socioeconomic countries $[17,18]$. Most of the patients in this study belonged to class V $(53.85 \%)$ followed by class IV $(43.85 \%)$ while one $(2.56 \%)$ patient belonged to class III of modified Kuppuswamy socioeconomic scale. These findings were in accordance with earlier reported studies $[19,20]$.

Most of the patients in present study were vegetarian $(89.74 \%)$. Out of 13 male patients $12(92.31 \%)$ and out of 26 female patients $23(88.46 \%)$ were vegetarian. Vegetarianism was significantly associated with severe anemia in the studies by Verma et al [20] and Kakkar et al. [21]. Malnutrition and anaemia are very closely related. In present study severe thinness $(\mathrm{BMI}<-3 \mathrm{SD})$ was found in $15.38 \%$ patients and thinness (BMI -2SD to $-3 \mathrm{SD}$ ) was found in $35.64 \%$ of the patients. These findings were similar to the studies by Chhabra et al. [13] and Viswanadhan K [14].

Most the patients in the present study were symptomatic from 15-30 days $(51.28 \%)$. The mean duration of hospital stay was $6.5( \pm 2.5)$ days. In this study $10.26 \%$ patients with iron deficiency anemia, $15.38 \%$ patients with megaloblastic anemia and $7.69 \%$ patients with dimorphic anemia were transfused packed red blood cells. The remaining patients were managed by oral hematinics.

Limitations- The present study was a hospital based retrospective study dependent on the review of case files of the patients. Certain socio-demographical parameters like type of family, parental educational status, history of worm infestation and menstrual history in female adolescents were not documented in the case records. Investigations like reticulocyte count, red cell distribution width (RDW), serum folate and vit $\mathrm{B}_{12}$ level and iron studies could have given strength to our study.

\section{Conclusion}

We conclude that Megaloblastic anemia is common in adolescents, which is caused by deficiency of either folate or B12 deficiency. It has a significant correlation with diet pattern as it is more common in vegetarian people and predominantly seen in low socioeconomic status. Along with iron and folic acid, B12 supplementation is needed through nutritional programmes.

Periodic screening of adolescents may detect anemia at early stage and also the need for these supplements. Education about proper dietary habits is very essential. Large scale prospective studies on the prevalence and etiology of severe anemia in adolescents are needed.

\section{What this study adds}

Megaloblastic anemia is common in adolescents presenting with severe anemia. It is more common inadolescents on vegetarian diet and belonging to low socioeconomic class.

Contributors: SS and MS have conceptualized the concept. SS, PK, AP and MS were involved into collection of data and its analysis. All authors approved the final manuscript.

Funding: Nil, Conflict of interest: None initiated, Perission from IRB: Yes

\section{References}

1. Mathur JSS. Preventive and Social Medicine, A comprehensive text book.1st ed. New Delhi: CBS Publishers and Distributors; 2007; 382-89.

2. Kishore J. Editor. National Health Programs of India. 6th ed. New Delhi: Century Publications; 2006; 82-84. 


\section{Case Report}

3. Nayar PD, Mehta R. Child Health. In: Gupta P, Ghai OP, Editors. Textbook of Preventive and Social Medicine. 2nd ed. New Delhi: CBS Publishers and Distributors; 2007; 428-37.

4. Shobha S, Sharada D. Efficacy of twice weekly iron supplementation in anemic adolescent girls. Indian Pediatr. 2003 Dec; 40(12):1186-90.

5. Choudhary A, Moses PD, Mony P, Mathai M. Prevalence of anaemia among adolescent girls in the urban slums of Vellore, south India. Trop Doct. 2006 Jul; 36 (3):167-9. doi:10.1258/004947506777978253

6. Roy S, Ray S. Prevention of malnutrition. J Indian Med Assoc. 2000 Sep;98(9):510-1.

7. Patra S, Pemde HK, Singh V, et al. Profile of adolescents with severe anemia admitted in a tertiary care hospital in northern India. Indian J Pediatr. 2011 Jul; 78 (7): 863-5. doi: 10.1007/s12098-010-0336-2. Epub 2011 Jan 8.

8. Kapur D, Agarwal KN, Agarwal DK. Nutritional anemia and its control. Indian J Pediatr. 2002 Jul;69 (7): 607-16.

9. Chaudhary SM, Dhage VR. A study of anemia among adolescent females in the urban area of nagpur. Indian J Community Med. 2008 Oct;33(4):243-5. doi: 10.4103/0970-0218.43230.

10. Thomas D, Chandra J, Sharma S, et al. Determinants of Nutritional Anemia in Adolescents. Indian Pediatr. 2015 Oct;52(10):867-9.

11. Khanduri U, Sharma A, Joshi A. Occult cobalamin and folate deficiency in Indians. Natl Med J India. 2005 Jul-Aug;18(4):182-3.

12. Haq Salma, Iqbal Nasir, Fayyaz Fatima et al. Serum B12 and folate levels in patients with megaloblastic change in the bone marrow. Biomedica Vol. 28. JanJune 2012; pp. 35-39.

13. Chhabra A, Chandar V, Gupta A, Chandra H. Megaloblastic anaemia in hospitalized children. Journal, Indian Academy of Clinical Medicine.2012;13(3):195-7

14. Viswanadham KK, Sahoo A. A study of clinical profile and factor associated with anemia in the school going children. International Medical Journal. September 2017; 4(a): 914-917.

15. Keikhaei B, Zandian K, Ghasemi A, Tabibi R. et al. Iron-deficiency anemia among children in southwest Iran. Food Nutr Bull. 2007 Dec; 28 (4):406-11. doi: $10.1177 / 156482650702800405$

16.DallmanPR, Yip R, JohnsonC.Prevalence and causes of anemia in the United States, 1976 to 1980. Am J Clin Nutr. 1984Mar;39(3):437-45.doi:10.1093/ajcn/39.3.437

17. Tolentino K, Friedman JF. An update on anemia in less developed countries. Am J Trop Med Hyg. 2007 Jul; 77 (1):44-51.

18. Balarajan Y, Ramakrishnan U, Ozaltin E, Anaemia in low-income and middle-income countries. Lancet. 2011 Dec 17;378(9809):2123-35. doi: 10.1016/ S01406736(10) 62304-5. Epub 2011 Aug 1.

19. Jain Neeraj, Jain Vibha Mangal. Prevalence of anemia in school children. Medical Practice and Review Feb 2012; Vol.3 (1):pp.1-4.

20. Verma M, Chhatwal J, Kaur G. et al. Prevalence of anemia among urban school children of Punjab. Indian Pediatr. 1998 Dec;35(12):1181-6.

21. Kakkar R, Kakkar M, Kandpal SD, Jethani S. Study of anemia in adolescent school girls of Bhopal. Indian J Community Health 2010; 22:38-40.

\section{How to cite this article?}

Kumar P, Sharma S, Sharma M, Patel A. Clinical profile of severe anemia in adolescents from a hilly terrain tertiary care hospital in north India. Int J Pediatr Res.2018;5(9):462-467. doi:10.17511/ijpr.2018.i09.06. 